\title{
A bi-objective optimization approach based on Lp-metric method in broiler production network: a case study.
}

\author{
Nacera TAHRAOUI ${ }^{1}$, Lamia SARI-TRIQUI ${ }^{1 *}$, and Mohammed BENNKROUF ${ }^{2}$ \\ ${ }^{1}$ Manufacturing Engineering Laboratory of Tlemcen (MELT), university of Tlemcen, BP 230, Tlemcen, Algeria. \\ ${ }^{2}$ Manufacturing Engineering Laboratory of Tlemcen (MELT), university of Tlemcen, BP 230, Tlemcen; ESSA Tlemcen, Algeria.
}

\begin{abstract}
In this work, we analyse the chicken production in a poultry network composed of a set of farms that serves a slaughterhouse in the city of Tlemcen. Each farm has a chicken house dedicated to breeding, and each chicken house has three breeding modes: manual breeding, semi-automatic breeding, and automatic breeding. And each mode consumes an appropriate energy level depending on the degree of automation used, which directly affects the quality of the chicken. The objective of this study is to determine the best energy adaptation within the farm to obtain good quality chickens. The problem of this activity is the choice of the right energy level of breeding, which consumes a minimum energy value, and gives a good quality of chickens. Knowing that the quality improves with the increase of energy, this study serves to develop mathematical modelling of two objectives: minimization of energy consumption and maximization of the chicken quality produced. The two objectives are optimized independently, and then they are joined by adapting the LP-metric method to help the breeders choose the optimal energy level to obtain good quality chickens.
\end{abstract}

\section{Introduction}

Among the sectors that have undergone an important evolution through time is the agri-food sector, whether for the vegetables and fruits consumption or the meat and chicken consumption (B. Satır and G. Yıldırım, 2020) [1]. More specifically, in the protein family, the broiler chicken is the most consumed product compared to other meats, and this is mainly due to its reasonable price, which is in line with the average individual's income, and its availability on the market justified by the short production cycle. (Kaci and Kheffache, 2016; Tahraoui et al. 2020) [2][3]. This encourages farmers to invest in this field of broiler breeding to conquer the market. But this market conquest remains a challenge in front of an increasingly demanding consumer. This requirement remains remarkable on the chicken quality. That is why many breeders are trying to find mechanisms to improve quality while keeping a minimum energy consumption.

The studied network consists of 40 farms serving the optimal quantity of chicken to satisfy the demands of the slaughterhouse, where it delivers the white meat to different retailers. Broilers can be classified into three different qualities according to the breeding type and the production environment that has been granted to them, taking into account the different energetic and environmental constraints. The levels of energy consumption for broiler production can be divided into three levels: a high-quality level, a medium quality level, and a level with degraded quality depending on the applied breeding conditions.
Our study aims to develop a multi-objective MILP modelling that takes into consideration the minimization of energy cost, and the maximization of the chicken's quality delivered to the slaughterhouses. And finally by combining the two objectives into a single function using the LP-metric method (A. Gharaei et al. 2017) [4]. Which is a multi-objective and multi-criteria decisionmaking method, that allows the decision-maker to prioritize objectives over others by assigning a different weight to each objective to find an intermediate solution that allows a balance between the different objectives to be achieved.

The broiler's quality depends mainly on the breeding environment, i.e. to obtain good quality chickens, it is necessary to adapt the good breeding conditions in the breeding farms. Broilers are delicate animals and need extreme care for their breeding. (M. PETRACCI et al. 2015) [5]

Broiler production requires the use of well-equipped farms with specialized human and material resources, these material resources require equipment with high electrical power for proper operation and production, which results in a very high energy cost for farmers. However, the use of adequate energy standards or slightly above average provides a higher quality, but impact the chicken cost price, on the other hand, the decrease of electricity consumption gives a lower quality of chicken.

The interrelationship between quality and energy consumption makes it difficult for individual farmers to decide between investing in high-quality broiler chicken with high-energy consumption or minimal use of energy

\footnotetext{
* Corresponding author: triquilamia@yahoo.fr
} 
resources which will degrade the quality of the chicken. Knowing that the good quality of the produced chicken suits the customers very well, but on the other hand, the low energy cost suits the farmers.

For this reason, we are interested in this type of problem to find a compromise between acceptable quality and average energy use. Which will perfectly fit with the requirements of both sides farmer and customer.

To better determine our research contribution, an overview of the works related to our study is presented in order to position our work in relation to existing works.

In this work, we have addressed two aspects, the first concerns chicken breeding in general in terms of planning and qualitative production, the second concerns energy consumption at the level of breeding sites. For the first time, we will quote the works related to production and broiler breeding.

(P. Demir et al. 2010) [6] Study the broiler production statistics in Turkey, in order to specify the main factors affecting the market demands, the quantities of produced chickens, and the broilers' selling price. (M. PETRACCI et al. 2015) [5] Examine the consequences of genetic selection leading to rapid broiler growth on white meat quality. (You P.-S., Hsieh Y.-C. 2018) [7] Study the broiler production planning for a single company by determining the number of chicks to be raised. (N. Praseeratasang et al. 2019) [8] establish a broiler production network schedule to organize the production and distribution to satisfy the demands of the studied network centers. (B. Satır et G. Yıldırım, 2020) [1] study the financial production planning in order to decide the purchase dates of the breeding chicks to meet the studied horizon demands. (N. Tahraoui et al. 2020) [3] propose a breeding schedule for a poultry network in the city of Tlemcen Algeria, in order to satisfy a determined average demand. (E. Brevik et al. 2020) [9] study the broiler production planning by specifying the fertilized egg quality assigned for each farm in the studied breeding network in order to maximize the chicken quality.

And among the researchers who have been interested in energy consumption in poultry networks, we rely on several works in this field. (M.D.Heidari, et al. 2011) [10] adapt a methodology to determine the value of energy consumption for broiler production. (N. Kythreotou et al. 2012) [11] analyze a network with an energy study for the energy consumption estimation for the livestock breeding in Cyprus. (U. Hanifah, et al. 2018) [12] carry out an economic study to calculate the operating cost of heating broiler houses with a solar air heater. (Y. Cui, et al. 2020) [13] are studying the impact of using renewable energy systems in broiler production. (A. Costantino et al. 2021) [14] evaluate the energy performance of livestock farms and poultry houses by proposing an energy approach to specify the best type of insulation envelopes for farms in terms of energy and finance.

Through the existing literature, we observe that some researchers have been interested in the notion of quality and the genetic aspect, other researchers have been interested in the energy aspect, or each objective is treated separately. Namely, these two objectives are contradictory, and treating them together allows us to provide a median solution that ensures a balance between quality and energy consumption, which motivated us to study the problem in a multi-objective context by taking into account the qualitative character and the notion of energy consumption.

After a presentation of the literature review. The rest of the paper is organized as follows: we will start with a description of the studied problem. A second part will be dedicated to the mathematical formulation and the resolution approach. Then a presentation of the obtained results by the Cplex solver followed by a discussion of the different experiments relating to the parameters variation, and finally we will finish with a conclusion and some perspectives.

\section{Problem description}

In this work, we studied a planning problem within the poultry logistic chain in the city of Tlemcen-Algeria, where we considered two objective functions: the minimization of the energy consumption and the maximization of the chicken quality. This chain is composed of a set of breeding farms $\mathbf{I}(\mathbf{i} \in \mathbf{I})$, each farm is equipped with human resources (workers) and specialized materials fundamental for the different manipulations (feeding, watering, cleaning, environment management, ventilation, heating, and lighting) to provide the optimal environmental conditions that ensure the proper fattening of chickens.

The broiler production is carried out by cycles of three months divided into two periods: the period (1) of fattening which lasts 45 days, followed by the period (2) estimated by one month mandatory for the sanitary vacuum.

The launching of the breeding activity within the farms is done according to a very precise protocol. Starting with a launch order established by the farm manager, which indicates the starting date of the breeding, the hen house to be used in terms of capacity. Each poultry house is determined by an energy level appropriate to the breeding capacity. In this work, we have considered three different energy levels: lower level, average level, and the maximum level, which reflect the operation of poultry houses in the network of the city of Tlemcen.

For the broiler breeding, several activities and manipulations are carried out within the farms in chronological order of the different operations: ventilation, environment management, lighting and heating, feed, and water distribution. The change lies in the operating mode of the activity, which can be manual, semi-automatic, or automatic. In the case of the manual mode, all the operations are done by workers. In the case of the semi-automatic, the activity is carried out by operators who use certain automated means, such as the distribution of feed and water, and in the case of the automatic mode, all operations are done automatically without the intervention of workers. Each breeding 
mode consumes appropriate energy that can be defined as follows:

\section{- The lower level of energy consumption:}

This level corresponds to manual operation. It is classified by the lowest level of energy consumption since all operations are done manually with the strict minimum of energy. This type of energy is used for breeding a small number of chickens varying from 2000 chickens to a maximum of 5000 chickens. This level is the lowest in energy consumption, but it provides the lowest quality of chicken.

\section{- The maximum level of energy consumption:}

This level corresponds to the automatic operation. It consumes a large value of energy because the different breeding operations are done automatically with a high power of electricity, as well as, the quantity of chickens bred is very large. This level has a very expensive energy cost. This expense affects mainly the profit of the breeder. Note that the quality of chickens is better.

\section{- The average level of energy consumption:}

This level is a combination of the two previous levels. The breeding operations are divided into two types of automatic operations like cleaning, management of the environment, ventilation, heating, lighting. And operations are carried out by operators who use some automated means, such as feeding and watering. This level generates medium-quality chickens and a somewhat high energy cost.

The problem in this type of network concerns the choice of the objective to be reached between minimum energy consumption and high quality, our study proposes a linear model based on the LP-metric method for an intermediate solution that merges the two objectives at the same time. By choosing the right management for his farm, he can achieve high-quality chickens with minimal energy costs.

\section{Mathematical formulation}

To simplify the modeling of the proposed problem, which concerns the chicken breeding network composed of 40 farms where each farm has a minimum and maximum capacity and adequate energy level. We have taken into consideration some assumptions expressed as follows:

-Each farm performs single breeding during the production horizon by choosing the breeding mode according to the energy level before starting the breeding.

-Each energy level has a minimum quantity of chicks to respect and a maximum quantity not to exceed.

-The energy consumption threshold depends on the production level used. used.

-Broiler quality depends on the energy consumption

-The slaughterhouse provides the total demand for broilers.

\subsection{Sets}

$\mathrm{i}$ : $\quad$ set of breeding farms $i \in \mathrm{I}$.

$\mathrm{j}$ : $\quad$ set of slaughter centers $\mathrm{j} \epsilon \mathrm{J}$.

$\mathrm{n}$ : energy consumption levels $\mathrm{n} \in \mathrm{N}$.

\section{3 parameters}

$\mathrm{FQ}_{\mathrm{i}}{ }^{\mathrm{n}}$ : $\quad$ the chicken quality factor of each farm $\mathrm{i}$ at the used energy level $n$.

$\mathrm{VE}_{\mathrm{i}}^{\mathrm{n}}$ : the value of used energy in each farm $\mathrm{i}$ at energy level $n$.

$\mathrm{CMX}_{\mathrm{i}}^{\mathrm{n}}$ : the maximum quantity of chickens in farm i for each energy level $n$.

$\mathrm{CMN}_{\mathrm{i}}^{\mathrm{n}}$ : the minimum quantity of chickens in farm $i$ for each energy level $n$.

A: a large number

\subsection{Decision variables}

$\mathrm{QL}_{\mathrm{i}}{ }^{\mathrm{n}}$ : the quantity of chickens supplied by farms $\mathrm{i}$ using energy consumption level $n$.

NBF : the number of farms chosen to breed chickens

$Y_{i}^{n}=\left\{\begin{array}{c}1 \text { if farm } \mathrm{i} \text { is chosen for breeding using } \\ \text { energy level } \mathrm{n} \\ 0 \text { si non }\end{array}\right.$

\subsection{The mathematical model}

Our study focuses on a supply chain of broiler chickens in the city of Tlemcen-Algeria. This network has a set of farms I ( $i \in I$ ), these farms breed chickens to satisfy the demand $\mathrm{Dj}$ of the slaughter center $\mathrm{j}(\mathrm{j} \in \mathrm{J})$. In this study, we have two objectives:

The first objective (F1) is to minimize the sum of the overall energy cost of breeding chickens within all the network farms, as given by equation (1).

And the second objective (F2) is to maximize the chicken's quality, which is represented by equation (2), respecting a certain constraint related to the studied case.

$$
\begin{aligned}
& \min \mathrm{F} 1=\sum_{\mathrm{i}} \sum_{\mathrm{n}} \mathrm{QL}_{\mathrm{i}}^{\mathrm{n}} * \mathrm{VE}_{\mathrm{i}}^{\mathrm{n}} \\
& \max \mathrm{F} 2=\sum_{\mathrm{i}} \sum_{\mathrm{n}} \mathrm{QL}_{\mathrm{i}}^{\mathrm{n}} * \mathrm{FQ}_{\mathrm{i}}^{\mathrm{n}}
\end{aligned}
$$

Under the constraints

$$
\begin{array}{lllll}
\mathrm{QL}_{\mathrm{i}}^{\mathrm{n}} & \mathrm{CMX}_{\mathrm{i}}^{\mathrm{n}} * \mathrm{Y}_{\mathrm{i}}^{\mathrm{n}} & \mathrm{i} & \mathrm{n} & \text { (3) } \\
\mathrm{QL}_{\mathrm{i}}^{\mathrm{n}} & \mathrm{CMN}_{\mathrm{i}}^{\mathrm{n}} * \mathrm{Y}_{\mathrm{i}}^{\mathrm{n}} & \mathrm{i} & \mathrm{n} & \text { (4) } \\
\sum_{\mathrm{n}} \mathrm{Y}_{\mathrm{i}}^{\mathrm{n}} & 1 & \mathrm{i} & & (5) \\
\mathrm{QL}^{\mathrm{n}} & \mathrm{A} * \mathrm{Y}_{\mathrm{i}}^{\mathrm{n}} & \mathrm{i} & \mathrm{n} & (6) \\
\mathrm{QL}^{\mathrm{n}} & \mathrm{Y}_{\mathrm{i}}^{\mathrm{n}} & \mathrm{i} & \mathrm{n} & \text { (7) } \\
\mathrm{NBF}=\sum_{\mathrm{i}} \sum_{\mathrm{n}} \mathrm{Y}_{\mathrm{i}}^{\mathrm{n}} & & & &
\end{array}
$$




$$
\begin{array}{llllll}
\sum_{\mathrm{i}} \sum_{\mathrm{n}} \mathrm{QL}_{\mathrm{i}}^{\mathrm{n}}=\mathrm{D}_{\mathrm{j}} & \mathrm{j} & \\
\mathrm{Y}_{\mathrm{i}}\{0,1\} & & & \mathrm{i} & \\
\mathrm{QL}_{\mathrm{i}}^{\mathrm{n}} \mathrm{R}^{+} \mathrm{NBF} & \mathrm{N} & \mathrm{i} & \mathrm{n}
\end{array}
$$

Constraints (3) and (4) ensure that the number of chickens bred on each farm I must be appropriate to the breeding capacities of the energy level used n. i.e. each energy level has a minimum capacity that must be respected and a maximum capacity that must not be exceeded. The set of constraints (5), (6), and (7) allow calculating the chicken quantity bred in each farm I using the energy level n. The constraint (8) calculates the number of chosen farms for breeding. Constraint (9) ensures that the sum of the quantities bred in farms I using energy levels n must satisfy the demand of center j. Finally, Constraint (10) indicates the binary nature of the decision variable Yin, and Constraint (11) indicates the positive nature of the number of chickens delivered and the number of the chosen farms.

\section{Resolution approach}

For the validation of our modeling, which concerns a poultry network composed of 40 farms for production and a slaughterhouse, that provides the total demand in the city of Tlemcen-Algeria.

We have implemented the proposed algorithm under the Cplex solver, proposing several scenarios by varying the uncertain demand. The goal is to find the best intermediate decision between the two objectives to be reached: the minimization of energy consumption and the maximization of quality.

To do this we used the LP-metric method which is a multi-objective decision-making method, this method allows providing an acceptable solution when it comes to contradictory objectives in various fields, and which has been the subject of work by several researchers. (S. M. Arabzad et al .2015) [15] study a location-allocation problem with two objectives: minimization of the total costs of the studied supply chain and minimization of the deterioration rate occurred by transport by adapting the LP metric method. Also, (A. Gharaei et al. 2017) [4]develop bi-objective mathematical modeling, the first objective is the minimization of storage costs and the second objective is the maximization of total profit of the studied chain using the LP-metric method. (B. Zeddam et al. 2020) [16] propose a bi-objective approach for a vehicle routing problem of the Algerian fuel distribution company NAFTAL in Algeria, whose objectives are the minimization of $\mathrm{CO} 2$ emissions, and the maximization of gain.

\subsection{Application of the LP-metric method on the case study}

For our study, which concerns broiler production, we considered two objectives: minimization of energy consumption and maximization of broiler quality. The LP-Metric method merges the two previous objectives into a single function given as follows (equation 12) respecting the same constraints mentioned before.

$$
\min \mathrm{FP}=\mathrm{w} 1 * \frac{\mathrm{F} 1 \quad \mathrm{~F} 1_{\text {optimal }}}{\mathrm{F} 1_{\text {optimal }}} \mathrm{w} 2 * \frac{\mathrm{F} 2 \mathrm{~F} 2_{\text {optimal }}}{\mathrm{F} 2_{\text {optimal }}}
$$

\subsection{The data}

To implement the method in our study, we considered some parameters given below. These parameters were collected from questionnaires from the farmers. All these data are summarized in tables 1 and 2.

Table 1 represents the slaughterhouse demands of each studied scenario. Table 2 shows for each energy level: the minimum and maximum breeding quantities, the unit cost of energy consumption, as well as the degree of broiler quality supplied, which is done by estimation on a scale from 1 to 10 .

Table1: The slaughterhouse demands for each scenario.

\begin{tabular}{llll}
\hline Scenario & Demand & Scenario & Demand \\
\hline $\mathbf{1}$ & 132000 & $\mathbf{4}$ & 264000 \\
\hline $\mathbf{2}$ & 176000 & $\mathbf{5}$ & 308000 \\
\hline $\mathbf{3}$ & 220000 & $\mathbf{6}$ & 352000 \\
\hline
\end{tabular}

Table2: Data related to energy consumption levels.

\begin{tabular}{llll}
\hline & $\begin{array}{l}\text { Lower } \\
\text { level }\end{array}$ & $\begin{array}{l}\text { Average } \\
\text { level }\end{array}$ & $\begin{array}{l}\text { Maximum } \\
\text { level }\end{array}$ \\
\hline $\begin{array}{l}\text { The minimum } \\
\text { breeding } \\
\text { quantity }\end{array}$ & 2000 & 4000 & 7000 \\
\hline $\begin{array}{l}\text { The maximum } \\
\text { breeding } \\
\text { quantity }\end{array}$ & 5000 & 8000 & 10000 \\
\hline $\begin{array}{l}\text { The unitary } \\
\text { cost of energy } \\
\text { consumption }\end{array}$ & 2 & 7 & 10 \\
\hline $\begin{array}{l}\text { The value of } \\
\text { broiler quality }\end{array}$ & 1 & 5 & 9 \\
\hline
\end{tabular}

\section{Results and discussion}

To compare the obtained results several simulations were performed on three different configurations:

- The first configuration of the objective of minimizing energy consumption

- The second configuration of maximizing the quality of broilers.

- The third configuration combines the previous objectives in a single objective.

And each configuration has been tested in several scenarios. The results are represented in Table 3 for the first configuration of minimization of energy consumption. Table 4 for the second configuration of maximization of chicken quality. And Table 6 for the third configuration and Figures 1 and 2 for the comparison of the three configurations. 


\subsection{The $1^{\text {st }}$ configuration: minimization of energy consumption cost}

Table 3: the results of the $1^{\text {st }}$ configuration of minimization of energy consumption cost.

\begin{tabular}{|c|c|c|c|c|c|c|}
\hline & \multirow{2}{*}{$\begin{array}{l}\text { The } \\
\text { demand }\end{array}$} & \multirow{2}{*}{$\begin{array}{l}\text { The } 1^{\text {tt }} \\
\text { objective }\end{array}$} & \multirow{2}{*}{$\begin{array}{l}\text { The } 2^{\text {rd }} \\
\text { objective }\end{array}$} & \multicolumn{3}{|c|}{$\begin{array}{l}\text { Assignment of farms on energy } \\
\text { consumption levels }\end{array}$} \\
\hline & & & & $\begin{array}{l}\text { Lower } \\
\text { level }\end{array}$ & $\begin{array}{l}\text { Average } \\
\text { level }\end{array}$ & $\begin{array}{l}\text { Maximum } \\
\text { level }\end{array}$ \\
\hline $\begin{array}{c}1^{*} \\
\text { Scenario }\end{array}$ & 132000 & 264000 & 132000 & 27 & $i$ & $i$ \\
\hline $\begin{array}{c}2^{\text {ud }} \\
\text { Scenario } \\
\end{array}$ & 176000 & 352000 & 176000 & 36 & $i$ & j \\
\hline $\begin{array}{c}3^{\text {rid }} \\
\text { Scenarlo } \\
\end{array}$ & 220000 & 715000 & 440000 & 33 & $?$ & j \\
\hline $\begin{array}{c}4^{\text {a }} \\
\text { Scenario }\end{array}$ & 264000 & 1398000 & 960000 & 18 & 22 & I \\
\hline $\begin{array}{c}5^{\mathrm{a}} \\
\text { Scenario } \\
\end{array}$ & 308000 & 2056000 & 1460000 & 4 & 36 & $i$ \\
\hline $\begin{array}{c}6^{\mathrm{a}} \\
\text { Scenario }\end{array}$ & 352000 & 2944000 & 2400000 & I & 24 & 16 \\
\hline
\end{tabular}

From the obtained results for the first configuration, optimization of the breeding network with minimal energy consumption (Table 3). We observe that the proposed model has allowed satisfying the total demand in all the proposed scenarios, in this configuration the most advantageous modes of breeding are the modes with minimal energy consumption. This is the case for scenario 1 (27 farms using the lower energy consumption level).

And scenario 2 (36 farms with the lower energy consumption level) for the demand satisfaction. While scenarios 3, 4, and 5 used two energy levels lower and average levels. starting with the lower level and to satisfy the rest of the demand the level 2 was solicited for some farms since their breeding capacity filled the rest of the production.

For scenario 6 , the best solution was to choose 24 farms at the average level of energy consumption and 16 farms at the maximum level since the main objective for each production unit is to satisfy the customers' demands. We also observe that the increase in demand allows a switch from one level to the other in an increasing manner until the total demand is satisfied.

This configuration minimizes energy consumption but provides a minimal quality of broiler chicken, which may dissatisfy customers or even result in a loss due to the non-consumption of this product as consumers become more and more exigent.

\subsection{The $2^{\text {nd }}$ configuration: maximization of broiler quality}

The results of the second configuration in table 4 , maximizing the broiler quality provided by the farms, give the total satisfaction of the given demand for all the scenarios.
Table 4: the results of the $2^{\text {nd }}$ configuration of maximization of broiler quality.

\begin{tabular}{|c|c|c|c|c|c|c|}
\hline & \multirow{2}{*}{$\begin{array}{l}\text { The } \\
\text { demand }\end{array}$} & \multirow{2}{*}{$\begin{array}{l}\text { The } 1^{\text {t }} \\
\text { objective }\end{array}$} & \multirow{2}{*}{$\begin{array}{l}\text { The } 2^{\text {ad }} \\
\text { objective }\end{array}$} & \multicolumn{3}{|c|}{$\begin{array}{l}\text { Assignment of farms on energy } \\
\text { consumption levels }\end{array}$} \\
\hline & & & & $\begin{array}{c}\text { Lower } \\
\text { level }\end{array}$ & $\begin{array}{c}\text { Average } \\
\text { level }\end{array}$ & $\begin{array}{c}\text { Maximum } \\
\text { level }\end{array}$ \\
\hline $\begin{array}{c}1^{\text {st }} \\
\text { Scenario }\end{array}$ & 132000 & 1320000 & 1188000 & 1 & 1 & 17 \\
\hline $\begin{array}{c}2^{\text {ed }} \\
\text { Scenario }\end{array}$ & 176000 & 1760000 & 1584000 & 1 & 1 & 19 \\
\hline $\begin{array}{c}3^{\text {rd }} \\
\text { Scenario }\end{array}$ & 220000 & 2200000 & 1980000 & 7 & 1 & $3 !$ \\
\hline $\begin{array}{c}4^{\mathrm{th}} \\
\text { Scenario }\end{array}$ & 264000 & 2640000 & 2376000 & $l$ & I & 37 \\
\hline $\begin{array}{c}5^{\text {th }} \\
\text { Scenario }\end{array}$ & 308000 & 3080000 & 2772000 & 1 & 1 & 40 \\
\hline $\begin{array}{c}6^{\mathrm{H}} \\
\text { Scenario }\end{array}$ & 352000 & 3520000 & 3168000 & 1 & I & 40 \\
\hline
\end{tabular}

The results of the second configuration in table 4, maximizing the broiler quality provided by the farms, give the total satisfaction of the given demand for all the scenarios. For this configuration, the model has chosen to breed adapting the third level with maximum energy consumption for all scenarios, since this configuration has as the main goal high-quality breeding.

The increase in demand from one scenario to the other has pushed the model to increase the number of farms chosen for breeding to satisfy the given demand.

This configuration provides a higher quality, which ensures customer satisfaction but disadvantages the farmers by the high energy consumption, which risks an abundance of the breeding activity and generates an imbalance in the consumption of white meat in the market.

The two previous configurations give contradictory solutions: when we chose to minimize the costs of energy consumption, the model chooses to breed by adapting the two minimal and average levels of energy consumption which corresponds to a low cost of energy consumption, but this selection gives chickens of low quality, but when we chose to maximize the quality of chickens delivered the model is selected to adapt the maximum level of energy whose chickens are of good quality, which gives a high value of energy cost. This contradiction made us adapt the LP-metric method to find an optimal solution for both objectives.

\subsection{The $3^{\text {rd }}$ configuration: LP-metric method}

Table 5: the results of the $3^{\text {rd }}$ configuration of LP metric method.

\begin{tabular}{|c|c|c|c|c|c|c|}
\hline & \multirow{2}{*}{$\begin{array}{c}\text { The } \\
\text { demand }\end{array}$} & \multirow{2}{*}{$\begin{array}{c}\text { The } 1^{*} \\
\text { objective }\end{array}$} & \multirow{2}{*}{$\begin{array}{l}\text { The } 2^{\text {an }} \\
\text { objective }\end{array}$} & \multicolumn{3}{|c|}{$\begin{array}{l}\text { Assignment of farms on energy } \\
\text { consumption levels }\end{array}$} \\
\hline & & & & $\begin{array}{c}\text { Lower } \\
\text { level }\end{array}$ & $\begin{array}{c}\text { Average } \\
\text { level }\end{array}$ & $\begin{array}{l}\text { Maximum } \\
\text { level }\end{array}$ \\
\hline $\begin{array}{c}1^{*} \\
\text { Scenario }\end{array}$ & 132000 & 264000 & 132000 & 27 & i & I \\
\hline $\begin{array}{c}2^{\text {ad }} \\
\text { Scenario }\end{array}$ & 176000 & 352000 & 176000 & 36 & ' & 1 \\
\hline $\begin{array}{c}3^{\text {nd }} \\
\text { Scenario }\end{array}$ & 220000 & 728000 & 460000 & 34 & 5 & 1 \\
\hline $\begin{array}{c}4^{\text {th }} \\
\text { Scenario }\end{array}$ & 264000 & 1528000 & 1240000 & 26 & 3 & 11 \\
\hline $\begin{array}{c}5^{\text {th }} \\
\text { Scenario }\end{array}$ & 308000 & 2296090 & 1940000 & 16 & 6 & 18 \\
\hline $\begin{array}{c}6^{\text {th }} \\
\text { Scenario }\end{array}$ & 352000 & 3520000 & 3168000 & ' & 1 & 40 \\
\hline
\end{tabular}


From the obtained results in Table 5 of the metric LP method. Knowing that we used the same parameters as the previous configurations. We observe that the obtained results by the method allowed to satisfy the total demand in each scenario, and provides an intermediate solution between the two objectives to be reached for each scenario. Remains the choice of the level used for the breeding depends mainly on the quantity of the total demand. Note that for scenarios 1 and 2 the model has selected to make the breeding using the minimal energy mode, and this is due to low total demand. On the other hand, when the demand is very high, the method solution obtained for a high level of breeding as presented by scenario 6 ; and when the range of demand varies from 220,000 and 308,000 chickens, we see from the results obtained that all levels were solicited for breeding in an optimal way, which corresponds to scenarios 3, 4, and 5, where the allocation and distribution of the number of breeding sites vary according to the increase in demand to meet the market requirements.

\subsection{The Comparison between the three configurations:}

In order to visualize the interest of the LP-metric method for our study, we have established a comparison between the three configurations for the two objectives of the study. The comparison is presented in figure 1 which corresponds to the minimization of energy consumption, and figure 2 which represents the maximization of the broiler quality.

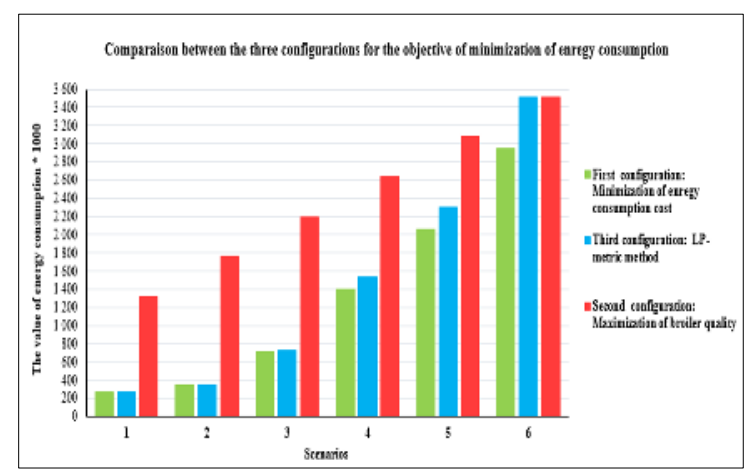

Fig. 1. Comparison between the three configuration for the objective of minimization of energy consumption.

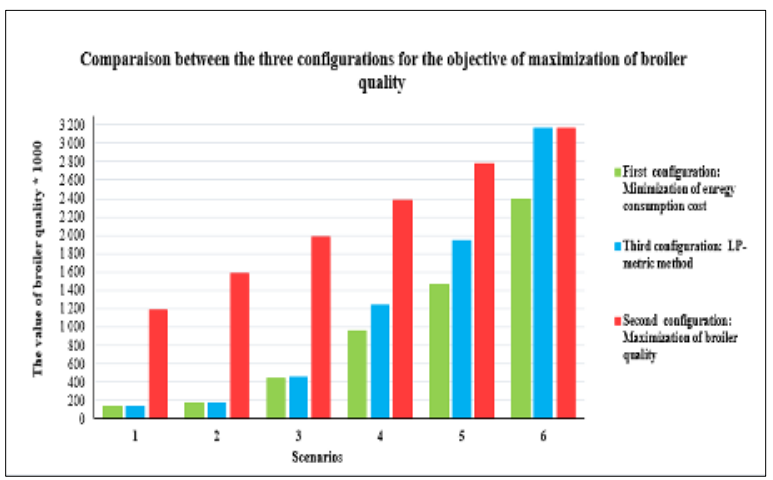

Fig. 2. Comparison between the three configuration for the objective of maximization broiler quality.
From the obtained results. We observe that the LP metric method gives a promising result for the studied poultry network. Since the given solutions represent favorable solutions when it involves combining the two objectives. This method gave the best compromise among the solutions obtained by the first two independent configurations.

We find that when the demand is low (scenarios 1 , 2 , and 3 ), the solutions given by the LP-metric method are more or less parallel with the solutions of the configuration where the objective is the minimization of energy consumption. On the other hand, when the total demand is high (scenario 6), the parallelism of the obtained results is oriented towards the solution of the configuration of the chicken quality maximization. That said, for the different intermediate scenarios between a minimum demand of 264,000 chickens and a maximum of 308,000 chickens, the method gave an intermediate solution.

\subsection{Impact of the weighting coefficients on the optimization of the studied problem:}

To visualize the impact of the weighting coefficients on the behavior of the LP-metric method in solving the studied problem. And to find the best weighting couple for the two studied objectives, we varied the values of the weighting coefficients as follows: [0.3 - 0.7], [0.5 $0.5]$, [0.7 - 0.3], the obtained results are grouped in Table 6 and presented in the figures $(3,4,5,6,7,8$, et 9$)$.

Table 6: the impact of the variation of weighting coefficient pair.

\begin{tabular}{ccccccc}
\hline & $\begin{array}{c}\text { The } \mathbf{1}^{\text {st }} \text { weighting } \\
\text { coefficient pair }\end{array}$ & \multicolumn{2}{c}{$\begin{array}{c}\text { The } \mathbf{2}^{\text {nd }} \text { weighting } \\
\text { coefficient pair }\end{array}$} & \multicolumn{2}{c}{$\begin{array}{c}\text { The } \mathbf{3}^{\text {rd }} \text { weighting } \\
\text { coefficient pair }\end{array}$} \\
\cline { 2 - 7 } & $\mathbf{0 . 7}$ & $\mathbf{0 . 3}$ & $\mathbf{0 . 5}$ & $\mathbf{0 . 5}$ & $\mathbf{0 . 3}$ & $\mathbf{0 . 7}$ \\
\hline Demand & $\begin{array}{c}\text { The } 1^{\text {st }} \\
\text { objective }\end{array}$ & $\begin{array}{c}\text { The } 2^{\text {nd }} \\
\text { objective }\end{array}$ & $\begin{array}{c}\text { The } 1^{\text {st }} \\
\text { objective }\end{array}$ & $\begin{array}{c}\text { The } 2^{\text {nd }} \\
\text { objective }\end{array}$ & $\begin{array}{c}\text { The } 1^{\text {st }} \\
\text { objective }\end{array}$ & $\begin{array}{c}\text { The } 2^{\text {nd }} \\
\text { objective }\end{array}$ \\
\hline $\mathbf{1 3 2 0 0 0}$ & 264000 & 132000 & 264000 & 132000 & 264000 & 132000 \\
\hline $\mathbf{1 7 6 0 0 0}$ & 352000 & 176000 & 352000 & 176000 & 352000 & 176000 \\
\hline $\mathbf{2 2 0 0 0 0}$ & 715000 & 440000 & 720000 & 460000 & 715000 & 440000 \\
\hline $\mathbf{2 6 4 0 0 0}$ & 1400000 & 976000 & 1528000 & 1240000 & 2640000 & 2376000 \\
\hline $\mathbf{3 0 8 0 0 0}$ & 2056000 & 1460000 & 2296000 & 1940000 & 3080000 & 2772000 \\
\hline $\mathbf{3 5 2 0 0 0}$ & 2296000 & 1940000 & 3080000 & 2772000 & 3080000 & 2772000 \\
\hline
\end{tabular}

From the obtained results. We observed that when the demand is low the variation of the weighting assigned to the two objectives: minimization of the consumed energy and maximization of the produced chickens quality does not influence the values of the two objective functions, the method opted to choose the breeding launch using the lower energy level as presented in the figures (Figure 3, Figure 4 and Figure $5)$. 


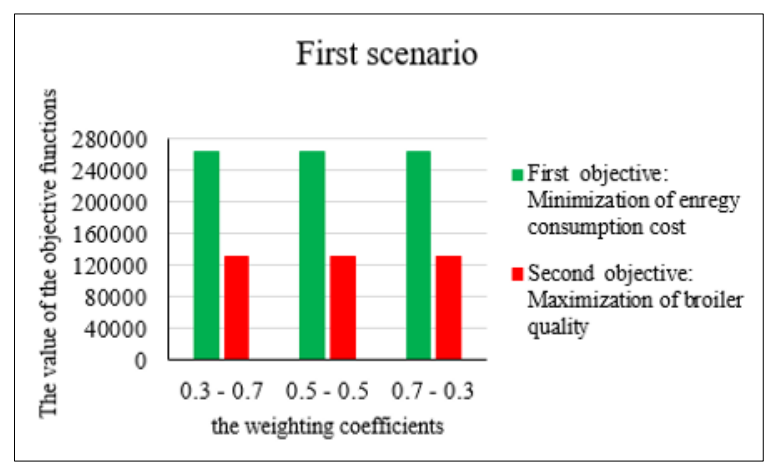

Fig.3. The impact of the weighting coefficients on the optimization of the two objectives for scenario 1 .

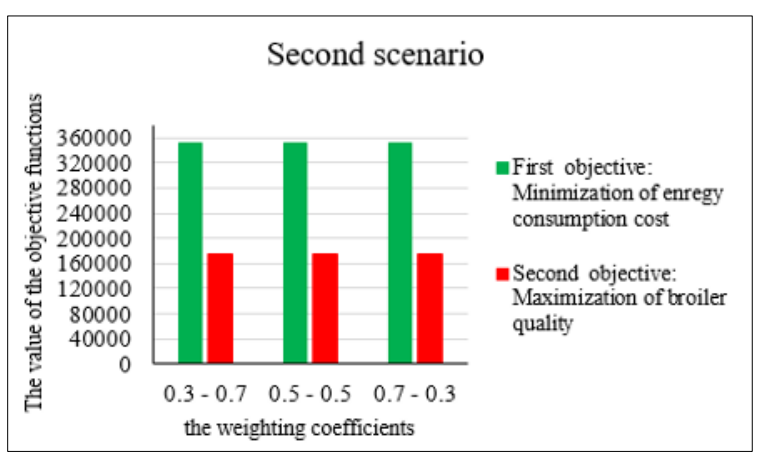

Fig.4. The impact of the weighting coefficients on the optimization of the two objectives for scenario 2 .

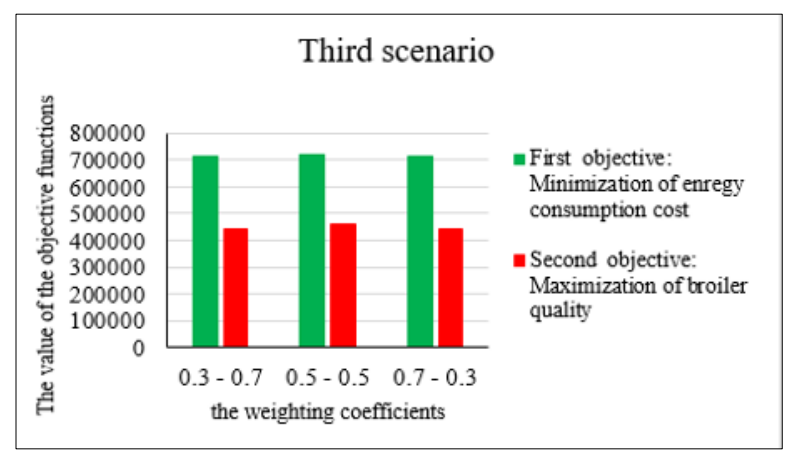

Fig.5. The impact of the weighting coefficients on the optimization of the two objectives for scenario 3.

When demand is very high, the method advantaged the broiler breeding by using the highest energy level whatever the weight of the coefficients. this can be justified by the high breeding capacity (Figure 6).

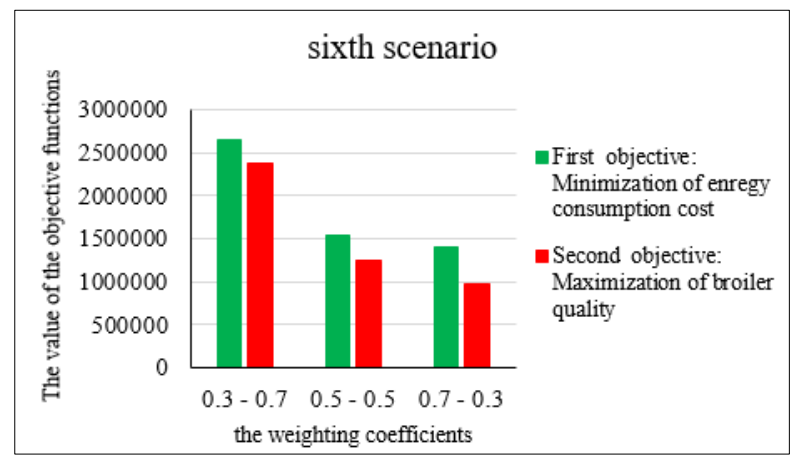

Fig.6. The impact of the weighting coefficients on the optimization of the two objectives for scenario 6 .

For the intermediate scenarios when the demand is 264,000 and 308,000 chickens, it can be observed, that the weight of the objective coefficients has a strong influence on the system's behavior, so for the pair (0.3 0.7) the method advantaged the second objective function (maximization of broiler quality) (Figure 7)

and for the pair $(0.7-0.3)$ the method advantages the first objective function (minimization of the energy consumed). And for the couple (0.5-0.5) it attributes an intermediate solution that ensures the balance between the two objective functions. (Figure 8)

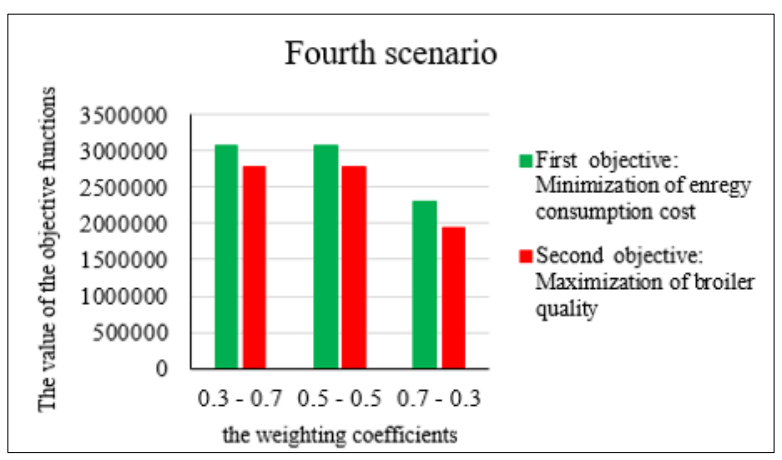

Fig.7. The impact of the weighting coefficients on the optimization of the two objectives for scenario 4 .

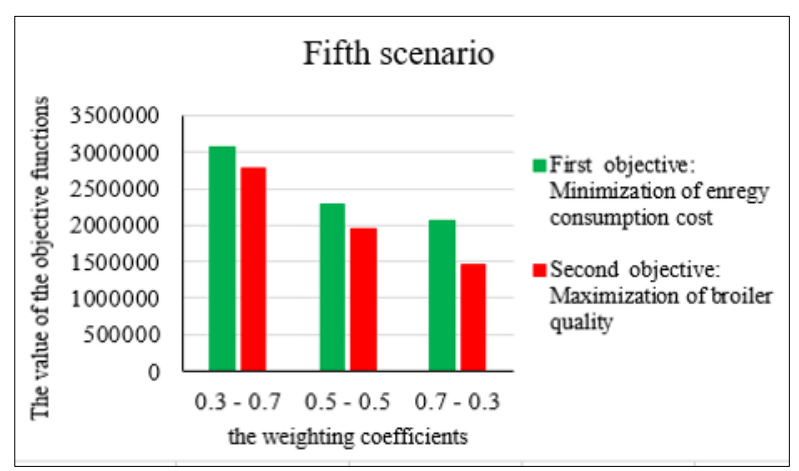

Fig.8. The impact of the weighting coefficients on the optimization of the two objectives for scenario 5. 


\section{Conclusion}

This research sheds light on broiler production in the city of Tlemcen. For this, we proposed a mathematical modeling MILP of two objectives: minimization of energy consumption and maximization of quality value. Our objective was to find a solution to a problem by taking into consideration several realistic characteristics. And in order to compare the validity of the results, we first studied the problem for each objective separately, which allowed us to specify the conflict of our study where the two objectives work in a contradictory way. Then we turned to the adaptation of the metric LP method, in order to find an optimal solution that merges the two study objectives.

The obtained results are very promising since they provide a decisional help for the different breeders containing the date of launching of the quantities to be bred and with what energetic level for an optimal intermediate solution between the qualitative degree of the broiler and the energy consumed for better production.

In the next part of this work, we will develop an extension of the work by addressing the large instances and solving them by a metaheuristic. Our future work is also oriented towards the adaptation of several energy sources in the studied system.

\section{References}

1. SATIR, Benhür et YILDIRIM, Gonca. A General Production and Financial Planning Model: Case of a Poultry Integration. Arabian Journal for Science and Engineering, 2020, p. 1-18.

2. Kaci, A., \&Kheffache, H. (2016). La production et la mise en marché du poulet de chair dans la wilaya de Médéa (Algérie): nécessité d'une coordination entre acteurs. les cahiers du cread, 118, 113-132.

3. TAHRAOUI, N., SARI, L. Triqui, et BENNEKROUF, M. Planning and synchronization of broiler production in a poultry network. In : 2020 IEEE 13th International Colloquium of Logistics and Supply Chain Management (LOGISTIQUA). IEEE, 2020. p. 1-6.

4. GHARAEI, Abolfazl, PASANDIDEH, Seyed Hamid Reza, et AKHAVAN NIAKI, Seyed Taghi. An optimal integrated lot sizing policy of inventory in a bi-objective multi-level supply chain with stochastic constraints and imperfect products. Journal of Industrial and Production Engineering, 2018, vol. 35, no 1, p. 6-20.

5. PETRACCI, Massimiliano, MUDALAL, S., SOGLIA, F., et al. Meat quality in fast-growing broiler chickens. World's Poultry Science Journal, 2015, vol. 71, no 2, p. 363-374.

6. DEMIR, P., ARAL, Y., CEVGER, Y., et al. An economic assessment of the chicken meat/feed price interactions in Turkish broiler sector. 2nd Mediterraean Summit of WPSA, Prospects of World Poultry: A Mediterrane an Perspective, 2010, p. 04-07.
7. YOU, Peng-Sheng et HSIEH, Yi-Chih. A study of production and harvesting planning for the chicken industry. Agricultural Economics, 2018, vol. 64, no 7, p. 316-327.

8. PRASEERATASANG, Natthanan, PITAKASO, Rapeepan, SETHANAN, Kanchana, et al. Adaptive Large Neighborhood Search to Solve Multi-Level Scheduling and Assignment Problems in Broiler Farms. Journal of Open Innovation: Technology, Market, and Complexity, 2019, vol. 5, no 3, p. 37.

9. BREVIK, Elisabeth, LAUEN, Anna Ø., ROLKE, Maria CB, et al. Optimisation of the broiler production supply chain. International Journal of Production Research, 2020, vol. 58, no 17, p. 52185237.

10. HEIDARI, M. D., OMID, M., et AKRAM, A. Energy efficiency and econometric analysis of broiler production farms. Energy, 2011, vol. 36, no 11, p. 6536-6541.

11. KYTHREOTOU, Nicoletta, FLORIDES, Georgios, et TASSOU, Savvas A. A proposed methodology for the calculation of direct consumption of fossil fuels and electricity for livestock breeding, and its application to Cyprus. Energy, 2012, vol. 40, no 1, p. 226-235.

12. HANIFAH, Umi, ADRIANSYAH, Willy, et al. Solar Air Heater for Preheating The Air of Broiler House. In : 2018 International Conference on Sustainable Energy Engineering and Application (ICSEEA). IEEE, 2018. p. 116-121.

13. CUI, Yuanlong, THEO, Elmer, GURLER, Tugba, et al. A comprehensive review on renewable and sustainable heating systems for poultry farming. International Journal of LowCarbon Technologies, 2020, vol. 15, no 1, p. 121142.

14. COSTANTINO, Andrea, CALVET, Salvador, et FABRIZIO, Enrico. Identification of energyefficient solutions for broiler house envelopes through a primary energy approach. Journal of Cleaner Production, 2021, p. 127639.

15. ARABZAD, S. Mohammad, GHORBANI, Mazaher, et ZOLFANI, Sarfaraz Hashemkhani. A multi-objective robust optimization model for a facility location-allocation problem in a supply chain under uncertainty. Engineering Economics, 2015, vol. 26, no 3, p. 227-238.

16. ZEDDAM, Besma, BELKAID, Fayçal, et BENNEKROUF, Mohammed. An efficient approach for solving integrated production and distribution planning problems: Cost vs. Energy. International Journal of Applied Logistics (IJAL), 2020, vol. 10, no 2, p. 25-44. 